\title{
Nonlinear dynamic analysis of low viscosity fluid-lubricated tilting-pad journal bearing for different design parameters
}

\author{
Yingze JIN ${ }^{1}$, Fei CHEN ${ }^{1}$, Jimin $\mathbf{X U}^{2}$, Xiaoyang YUAN ${ }^{1, *}$ \\ ${ }^{1}$ Key Laboratory of Education Ministry for Modern Design and Rotor-Bearing System, Xi'an Jiaotong University, Xi'an 710049, China \\ ${ }^{2}$ Institute of Tribology, School of Mechanical Engineering, Hefei University of Technology, Hefei 230009, China \\ Received: 11 January 2019 / Revised: 19 April 2019 / Accepted: 26 June 2019 \\ (C) The author(s) 2019.
}

\begin{abstract}
To reveal nonlinear dynamic rules of low viscosity fluid-lubricated tilting-pad journal bearings (TPJBs), the effects of design parameters on journal center orbits and dynamic minimum film thicknesses of waterlubricated TPJBs with and without static loads are investigated. The hydrodynamic bearing force used in the nonlinear dynamic analysis is an approximate analytical solution including the turbulence effect. The results reveal the methods for vibration suppression and load capacity improvement and give an optimal pivot offset and clearance ratio that can maximize the minimum film thickness. The results also show that four-pad TPJBs with loads between pads are preferred due to good dynamic performance and load capacity. This study would provide some guidance for nonlinear design of low viscosity fluid-lubricated TPJBs under dynamic loads.
\end{abstract}

Keywords: journal center orbit; dynamic minimum film thickness; tilting-pad journal bearing; bearing design parameter

\section{Introduction}

With good stability on rotor systems, tilting-pad journal bearings (TPJBs) have been widely applied in large-scale rotating machineries, such as steam turbines, gas turbines, and nuclear reactor coolant pumps. The representative research of tilting-pad thrust bearings focuses on the effects of surface roughness [1] and lifting pockets [2] on bearing performance. Water has been gradually used as the journal bearing lubricant in ship stern shafts, hydraulic turbines, and water pumps instead of oil. It is worth mentioning that waterlubricated tilting-pad journal/thrust bearings have been applied to the nuclear reactor coolant pump of the third generation AP1000 reactor.

Because of the nonlinear effect of hydrodynamic bearing force, the dynamic performance of a TPJB-rotor system cannot be accurately evaluated using a linear model. Because of the low viscosity characteristic of water, water-lubricated TPJBs can perform higher stability but lower load capacity compared with oillubricated TPJBs. Because of the high operational Reynolds number of water film, water-lubricated TPJBs may be in the turbulent lubrication and generate the turbulent force. Therefore, it is significant to perform a nonlinear dynamic analysis especially on the nonlinear dynamic behavior and dynamic load capacity of a water-lubricated TPJB.

There have been a lot of studies focusing on the nonlinear dynamic analysis of a TPJB up to now. Kim and Palazzolo [3] investigated the effects of pad preloads, pivot offsets, and lubricant viscosities on the nonlinear response and bifurcation using numerical continuation method. Bai et al. [4] investigated the linear critical speed and some nonlinear dynamic characteristics of a double cantilever rotor in a large-scale turbo expander, and Li et al. [5] studied those considering the viscositytemperature effect of fluid film. Cha and Glavatskih [6] investigated the nonlinear dynamic behavior of vertical and horizontal rigid rotors supported by

* Corresponding author: Xiaoyang YUAN, E-mail: zonghezu_xjtu@163.com 


\begin{tabular}{|c|c|c|c|}
\hline \multicolumn{4}{|c|}{ Nomenclature } \\
\hline$P_{i}$ & Dimensionless film pressure & $\omega$ & Rotational angular speed \\
\hline$H_{i}$ & Dimensionless film thickness & $\mu$ & Fluid viscosity \\
\hline$L$ & Pad length & $H_{\mathrm{m}}$ & Dimensionless mean film thickness \\
\hline$D$ & Journal diameter & $\phi_{\text {in, }} \phi_{\text {out }}$ & Position angles at the film beginning and end \\
\hline$\eta$ & Length-to-diameter ratio & $M_{\mathrm{j}}$ & Dimensionless journal mass \\
\hline$\tau$ & Dimensionless time & $\varepsilon_{\mathrm{u}}$ & Unbalance eccentricity ratio \\
\hline$\phi, \lambda$ & $\begin{array}{l}\text { Dimensionless circumferential and axial } \\
\text { coordinates }\end{array}$ & $F_{X}, F_{Y}$ & $\begin{array}{l}\text { Dimensionless hydrodynamic bearing force } \\
\text { in } X \text { and } Y \text { directions }\end{array}$ \\
\hline$X, Y$ & Dimensionless Cartesian coordinates & $W_{X}, W_{Y}$ & Load components in $X$ and $Y$ directions \\
\hline$K_{\phi}, K_{\lambda}$ & Turbulence coefficients & $\delta_{i}^{\prime \prime}$ & Dimensionless pad tilt acceleration \\
\hline$A$ & Preload factor & $\bar{M}_{i}$ & Dimensionless hydrodynamic force moment \\
\hline$\beta_{i}$ & Pivot position angle & & acting on pad \\
\hline$\varepsilon$ & Journal eccentricity ratio & $\bar{J}$ & Dimensionless pad moment of inertia \\
\hline$\theta$ & Journal attitude angle & $\rho_{\mathrm{p}}$ & Pad density \\
\hline$\delta_{i}$ & Dimensionless pad tilt angle & $h_{\mathrm{p}}$ & Pad thickness \\
\hline$c$ & Radial pad clearance & $\alpha$ & Pad arc angle \\
\hline$R$ & Journal radius & $\zeta$ & Pivot offset \\
\hline$\psi$ & Clearance ratio & $\varepsilon^{\prime}, \varepsilon \theta^{\prime}$ & Dimensionless radial and tangential journal \\
\hline $\operatorname{Re}$ & Reynolds number used in the equations & & velocity \\
\hline $\operatorname{Rem}_{\mathrm{m}}$ & Mean Reynolds number & $\delta_{i}^{\prime}$ & Dimensionless pad tilt velocity \\
\hline Rel & Local Reynolds number & $x, y$ & Journal displacements in $X$ and $Y$ directions \\
\hline$\rho$ & Fluid density & $T$ & Water temperature \\
\hline
\end{tabular}

compliant liner TPJBs and compared it with white metal TPJBs considering different preload factors, pivot offsets, compliant liner elasticity, and pad inclinations. Okabe [7] proposed an analytical hydrodynamic bearing force model using the short bearing method with the effects of turbulence and fluid inertia and investigated the effects of radial clearances, preload factors, number of pads, load positions, and pivot offsets on the rotor dynamic behavior with and without the inertia effect. Abu-Mahfouz and Adams [8] investigated the nonsynchronous and chaotic behaviors under two loading mechanisms of on-pad load and no static biasing load by changing several bearing design parameters. Ying et al. [9] compared the nonlinear dynamic characteristics including bifurcations, time histories, phase trajectories, frequency spectrums, and Poincaré maps with and without the pad inertia effect. Lu et al. [10] investigated the nonlinear dynamic behavior of a rigid rotor supported by fixed-tilting-pad journal bearings and analyzed the effects of pivot offsets and preload factors on journal center orbits. White et al. [11] investigated the effect of bearing clearances on the rotor dynamic behavior that includes whirl orbits and frequency spectrums of a twelve stage vertical pump rotor with and without the wear ring effect. Monmousseau et al. [12] performed a transient thermoelastohydrodynamic (TEHD) analysis on the shaft orbit, minimum film thickness, maximum pressure, and maximum temperature for different unbalance eccentricities. Brancati et al. [13] proposed a method to predict the nonlinear stability by the limit stability curve separating the stable synchronous motion from the unstable one with one half rotational frequency. Gadangi and Palazzolo [14] investigated the transient journal orbit, minimum film thickness, and maximum film temperature considering the pad deformation and fluid film temperature. Desbordes et al. [15] investigated the effect of pad deformation on transient journal orbits, minimum film thicknesses, and maximum pressures for different unbalance masses. Hei et al. 
[16] investigated the nonlinear dynamic behavior and bifurcation of a rod fastening rotor supported by fixed-tilting-pad journal bearings by orbit diagrams, time series, frequency spectrums, and Poincaré maps considering different pivot offsets and preload factors.

There are only a few studies focusing on the static and dynamic analyses of water-lubricated TPJBs with the turbulent effect. Okabe and Cavalca [17] introduced the turbulence model of Capone into the short bearing model and investigated the effects of preload factors, number of pads, radial clearances, pad positions, and pivoting angles on journal center orbits with and without the turbulence effect. Armentrout et al. [18] investigated the effects of turbulence and convective fluid inertia on the film pressure, load capacity, and power loss using the CFD model and conventional Reynolds solution. Li et al. [19] investigated the film temperature distribution, bearing force, stiffness, and damping considering $\mathrm{Ng}$ and Pan turbulence model and temperature-viscosity effects. Jin et al. [20] developed the database method for fast solving the hydrodynamic bearing force by introducing $\mathrm{Ng}$ and Pan turbulence model and the adiabatic energy equation and compared the nonlinear dynamic behavior with and without the turbulent and thermal effects.

Based on the above research, the nonlinear dynamics of TPJBs can be summarized as follows: i) synchronous behavior; ii) nonsynchronous behavior; iii) bifurcation and stability; iv) critical characteristic; v) reliability. Moreover, the nonlinear dynamic research of waterlubricated TPJBs focuses on the dynamic behavior including the turbulence effect. However, the integrated nonlinear analyses on the dynamic behavior and dynamic load capacity of water-lubricated TPJBs under different bearing design parameters have not been reported.

The objective of this paper is to reveal the nonlinear dynamic rules of journal center orbits and dynamic minimum film thicknesses of a water-lubricated TPJB with and without the static load under different bearing design parameters, thus provide some references for the nonlinear design and safe operation of waterlubricated TPJBs. The current work investigates the effects of preload factors, pivot offsets, length-todiameter ratios, clearance ratios, pad arc angles, water temperatures, number of pads, and load directions on journal center orbits and dynamic minimum film thicknesses.

\section{Governing equations}

The main research object is a water-lubricated fourpad TPJB, whose geometry is shown in Fig. 1. The dimensionless turbulent Reynolds equation for the $i$-th pad under the isothermal, incompressible and inertialess flow conditions can be written as

$$
\frac{\partial}{\partial \phi}\left(\frac{H_{i}^{3}}{K_{\phi}} \frac{\partial P_{i}}{\partial \phi}\right)+\frac{1}{\eta^{2}} \frac{\partial}{\partial \lambda}\left(\frac{H_{i}^{3}}{K_{\lambda}} \frac{\partial P_{i}}{\partial \lambda}\right)=3 \frac{\partial H_{i}}{\partial \phi}+6 \frac{\partial H_{i}}{\partial \tau}
$$

where $P_{i}$ is dimensionless film pressure; $H_{i}$ is dimensionless film thickness; $\eta=L / D$ is length-to-diameter ratio, where $L$ and $D$ are pad length and journal diameter, respectively; $\tau$ is dimensionless time; $\phi$ and $\lambda$ are dimensionless circumferential and axial coordinates, respectively; and $K_{\phi}$ and $K_{\lambda}$ are turbulence coefficients. The dimensional ratios of dimensionless parameters in this paper are shown in Appendix.

The dimensionless film thickness $H_{i}$ is given by

$$
H_{i}=1-A \cos \left(\beta_{i}-\phi\right)+\varepsilon \cos (\phi-\theta)+\frac{\delta_{i}}{\psi} \sin \left(\beta_{i}-\phi\right)
$$

where $A$ is preload factor, $\beta_{i}$ is pivot position angle, $\varepsilon$ is journal eccentricity ratio, $\theta$ is journal attitude angle, $\delta_{i}$ is dimensionless pad tilt angle, and $\psi=c / R$ is clearance ratio, where $c$ and $R$ are radial pad clearance and journal radius, respectively.

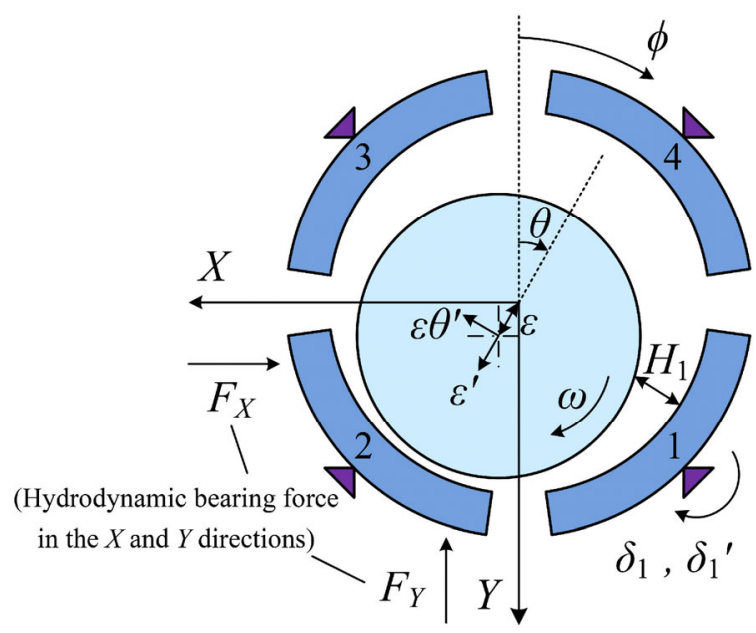

Fig. 1 Geometry and coordinate of a four-pad TPJB. 
The turbulence coefficients of $\mathrm{Ng}$ and Pan [21] are given by

$$
K_{\phi}=1+\frac{0.0136}{12} \operatorname{Re}^{0.9}, \quad K_{\lambda}=1+\frac{0.0043}{12} \operatorname{Re}^{0.96}
$$

where Re is Reynolds number used in the equations.

Three kinds of flow regime (laminar, transitional, and turbulent flow regime), which are delimited by two critical Reynolds numbers: 800 and 1,500 [22, 23], may exist in the fluid film. Re can be defined as

$$
\begin{aligned}
& \operatorname{Re}= \\
& \left\{\begin{array}{lll}
0, & \operatorname{Re}_{\mathrm{m}} \leq 800 & \text { (laminar) } \\
c_{1} \mathrm{Re}_{\mathrm{m}}^{3}+c_{2} \mathrm{Re}_{\mathrm{m}}^{2}+c_{3} \operatorname{Re}_{\mathrm{m}}+c_{4}, & 800<\operatorname{Re}_{\mathrm{m}}<1500 & \text { (transitional) } \\
\operatorname{Re}_{1}, & \operatorname{Re}_{\mathrm{m}} \geq 1500 & \text { (turbulent) }
\end{array}\right.
\end{aligned}
$$

where $c_{1-4}$ are determined by ensuring the continuity of Re and its first derivative at the beginning and end of the transitional zone, $\operatorname{Re}_{\mathrm{m}}$ is mean Reynolds number, and $\mathrm{Re}_{1}$ is local Reynolds number, which can be expressed as

$$
\mathrm{Re}_{\mathrm{m}}=\frac{\rho \omega R H_{\mathrm{m}} c}{\mu}, \mathrm{Re}_{1}=\frac{\rho \omega R H_{i} c}{\mu}
$$

where $\rho$ is fluid density, $\omega$ is rotational angular speed, $\mu$ is fluid viscosity, and $H_{\mathrm{m}}$ is dimensionless mean film thickness, defined as

$$
H_{\mathrm{m}}=\frac{1}{\phi_{\text {out }}-\phi_{\text {in }}} \int_{\phi_{\text {in }}}^{\phi_{\text {out }}} H_{i} \mathrm{~d} \phi
$$

where $\phi_{\text {in }}$ and $\phi_{\text {out }}$ are position angles at the film beginning and end, respectively.

The dimensionless motion equation of the journal and pads can be described as

$$
\left\{\begin{array}{l}
M_{\mathrm{j}} X^{\prime \prime}=M_{\mathrm{j}} \varepsilon_{\mathrm{u}} \sin \tau-F_{X}+W_{X} \\
M_{\mathrm{j}} Y^{\prime \prime}=M_{\mathrm{j}} \varepsilon_{\mathrm{u}} \cos \tau-F_{Y}+W_{Y} \\
\bar{J} \delta_{i}^{\prime \prime}=\bar{M}_{i}
\end{array}\right.
$$

where $M_{\mathrm{j}}$ is dimensionless journal mass, $\varepsilon_{\mathrm{u}}$ is unbalance eccentricity ratio; $F_{X}$ and $F_{Y}$ are dimensionless hydrodynamic bearing force in $X$ and $Y$ directions, respectively; $W_{X}$ and $W_{Y}$ are load components in $X$ and $Y$ directions, respectively; $\delta_{i}^{\prime \prime}$ is dimensionless pad tilt acceleration, $\bar{M}_{i}$ is dimensionless hydrodynamic force moment acting on the pad, and $\bar{J}$ is dimensionless pad moment of inertia, whose normalized form is approximate to Eq. (8):

$$
J=\rho_{\mathrm{p}} L\left\{\begin{array}{l}
\alpha\left[\frac{1}{2}\left(R+h_{\mathrm{p}}\right)^{2} R^{2}+\frac{1}{4}\left(R+h_{\mathrm{p}}\right)^{4}-\frac{3}{4} R^{4}\right] \\
+\frac{2}{3}[\sin (\alpha-\alpha \zeta)+\sin (\alpha \zeta)]\left[R^{4}-\left(R+h_{\mathrm{p}}\right)^{3} R\right]
\end{array}\right\}
$$

where $\rho_{\mathrm{p}}$ is pad density, $h_{\mathrm{p}}$ is pad thickness, $\alpha$ is pad arc angle, and $\zeta$ is pivot offset.

Through the equation description on this section, some discussion is given. Three turbulent lubrication theories are at present available [21]: i) Constantinescu; ii) Ng, Pan, and Elrod; iii) Hirs. The first two theories predict the same and simple form of the classical isothermal turbulent Reynolds equation, namely Eq. (1). The results obtained by the three turbulent models of Constantinescu model, $\mathrm{Ng}$ and Pan model, and Elrod and $\mathrm{Ng}$ model are similar [23]. However, $\mathrm{Ng}$ and Pan model is appropriate for the derivation of analytical hydrodynamic force due to the turbulence coefficients approximating a linear function of film thickness. Therefore, the modified Reynolds equation with $\mathrm{Ng}$ and Pan turbulence model is used. In addition, the difference in governing equations between waterlubricated and oil-lubricated TPJBs lies in turbulent and thermal effects. In general, Navier-Stokes equation or the turbulent Reynolds equation is indispensable for water-lubricated TPJBs due to the lower viscosity and higher Reynolds number, while the energy equation is indispensable for oil-lubricated TPJBs due to the higher viscosity and temperature rise.

\section{Approximate analytical solution of hydrodynamic bearing force}

Equation (1) is solved with the method of separation of variables under the dynamic Gümbel boundary condition [24].

The dimensionless film thickness can be expressed as

$$
H_{i}=1+\varepsilon_{i} \cos \varphi\left(\varphi=\phi-\theta_{i}\right)
$$

where 


$$
\begin{aligned}
& \varepsilon_{i}=\sqrt{\left(\begin{array}{l}
\left.\varepsilon \cos \theta+\frac{\delta_{i}}{\psi} \sin \beta_{i}-A \cos \beta_{i}\right)^{2} \\
+\left(\varepsilon \sin \theta-\frac{\delta_{i}}{\psi} \cos \beta_{i}-A \sin \beta_{i}\right)^{2},
\end{array}\right.} \\
& \cos \theta_{i}=\left(\varepsilon \cos \theta+\frac{\delta_{i}}{\psi} \sin \beta_{i}-A \cos \beta_{i}\right) / \varepsilon_{i}, \\
& \sin \theta_{i}=\left(\varepsilon \sin \theta-\frac{\delta_{i}}{\psi} \cos \beta_{i}-A \sin \beta_{i}\right) / \varepsilon_{i}
\end{aligned}
$$

Assuming that the film pressure can be separated in the following multiplicative form:

$$
P_{i}(\varphi, \lambda)=P_{\mathrm{L}}(\varphi) P^{*}(\lambda)
$$

where $P_{\mathrm{L}}$ is infinitely long bearing pressure and solved by Eq. (12):

$$
\frac{\mathrm{d}}{\mathrm{d} \varphi}\left(\frac{H_{i}^{3}}{K_{\phi}} \frac{\mathrm{d} P_{\mathrm{L}}}{\mathrm{d} \varphi}\right)=-3\left(\varepsilon_{i}-2 \varepsilon_{i} \theta_{i}^{\prime}\right) \sin \varphi+6 \varepsilon_{i}^{\prime} \cos \varphi
$$

where

$$
\begin{aligned}
\varepsilon_{i}^{\prime}= & \left(\varepsilon^{\prime} \cos \theta-\varepsilon \theta^{\prime} \sin \theta+\frac{\delta_{i}^{\prime}}{\psi} \sin \beta_{i}\right) \cos \theta_{i} \\
& +\left(\varepsilon^{\prime} \sin \theta+\varepsilon \theta^{\prime} \cos \theta-\frac{\delta_{i}^{\prime}}{\psi} \cos \beta_{i}\right) \sin \theta_{i}, \\
\varepsilon_{i} \theta_{i}^{\prime}= & \left(\varepsilon^{\prime} \sin \theta+\varepsilon \theta^{\prime} \cos \theta-\frac{\delta_{i}^{\prime}}{\psi} \cos \beta_{i}\right) \cos \theta_{i} \\
& -\left(\varepsilon^{\prime} \cos \theta-\varepsilon \theta^{\prime} \sin \theta+\frac{\delta_{i}^{\prime}}{\psi} \sin \beta_{i}\right) \sin \theta_{i}
\end{aligned}
$$

where $\varepsilon^{\prime}$ and $\varepsilon \theta^{\prime}$ are dimensionless radial and tangential journal velocity, respectively, and $\delta_{i}{ }^{\prime}$ is dimensionless pad tilt velocity.

$P^{*}$ is given by

$$
P^{*}(\lambda)=1-\frac{\cosh (q \lambda)}{\cosh q}
$$

where

$q=$

$\eta \sqrt{-\frac{\int_{\varphi_{\text {in }}}^{\varphi_{\text {out }}} \frac{K_{\lambda} \sin \left(\varphi-\varphi_{\text {in }}\right)\left[-3\left(\varepsilon_{i}-2 \varepsilon_{i} \theta_{i}^{\prime}\right) \sin \varphi+6 \varepsilon_{i}^{\prime} \cos \varphi\right]}{H_{i}^{3}} \mathrm{~d} \varphi}{\int_{\varphi_{\text {in }}}^{\varphi_{\text {out }}} P_{\mathrm{L}} \sin \left(\varphi-\varphi_{\text {in }}\right) \mathrm{d} \varphi}}$
The dimensionless hydrodynamic bearing force in $X$ and $Y$ directions is given by

$$
\begin{aligned}
& F_{X}=\sum_{i} \int_{-1}^{1} \int_{\phi_{\text {in }}}^{\phi_{\text {out }}}-P_{i} \sin \phi \mathrm{d} \phi \mathrm{d} \lambda, \\
& F_{Y}=\sum_{i} \int_{-1}^{1} \int_{\phi_{\text {in }}}^{\phi_{\text {out }}}-P_{i} \cos \phi \mathrm{d} \phi \mathrm{d} \lambda
\end{aligned}
$$

The complex integrals are analytically solved with Mathematica.

\section{Model verification}

Figure 2 compares the analytical solution and a CFD solution [18] of pad centerline pressure for a single pad of a water-lubricated TPJB. Both the two solutions include the turbulence effect and leave out the fluid inertia effect. The analytical solution is on the whole in good agreement with the CFD solution. The maximum pressure with the analytical expression is only $2.14 \%$ higher than that with CFD. The film rupture angle with the analytical expression is about 5 degree less than that with CFD because of their different boundary conditions.

\section{Results and discussion}

The water-lubricated TPJB parameters used in the calculation are listed in Table 1 , and the initial values are underlined and shown in bold. Equation (7) is solved with precise time-integration method. The steady state response data is extracted to investigate the effects of bearing design parameters on journal center orbits and dynamic minimum film thicknesses of TPJBs with and without static loads.

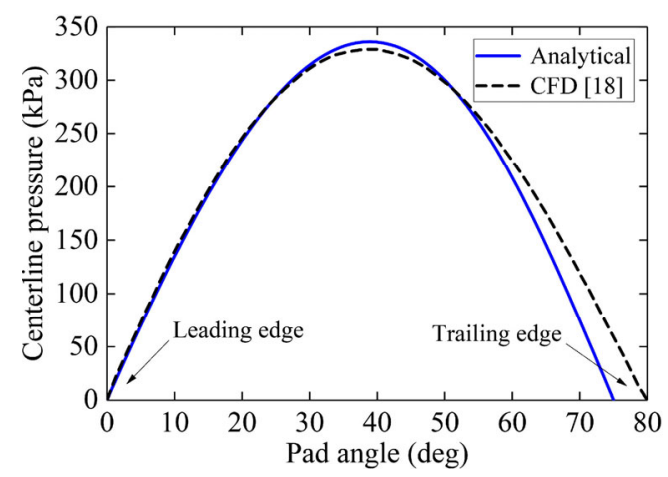

Fig. 2 Analytical and CFD solutions of water-lubricated pad centerline pressure for turbulent operation. 
Table 1 Structural and operational parameters of a waterlubricated TPJB.

\begin{tabular}{cc}
\hline Parameter & Value \\
\hline Journal diameter $(D)$ & $416 \mathrm{~mm}$ \\
Pad thickness $\left(h_{\mathrm{p}}\right)$ & $40 \mathrm{~mm}$ \\
Pad density $\left(\rho_{\mathrm{p}}\right)$ & $7.85 \times 10^{3} \mathrm{~kg} \cdot \mathrm{m}^{-3}$ \\
Rotational speed & $1,500 \mathrm{rpm}$ \\
Journal mass & $9,000 \mathrm{~kg}$ \\
Unbalance mass eccentricity & $200 \mu \mathrm{m}$ \\
$X$-direction load & 0 \\
$Y$-direction load & $0,100 \mathrm{kN}$ \\
Length-to-diameter ratio $(\eta)$ & $0.3,0.6, \underline{\mathbf{0 . 9}}, 1.2,1.5$ \\
Number of pads & $3, \underline{\mathbf{4}}, 5,6,7$ \\
Preload factor $(A)$ & $0.4, \underline{\mathbf{0 . 5}}, 0.6,0.7,0.8$ \\
Pivot offset $(\zeta)$ & $\underline{\mathbf{5 0} \%}, 56 \%, 62^{\circ}, 68 \%, 74 \%$ \\
Pad arc angle $(\alpha)$ & $45^{\circ}, 55^{\circ}, 65^{\circ}, 75^{\circ}, \underline{\mathbf{8 0}}, 85^{\circ}$ \\
Load direction angle & $135^{\circ}, 157.5^{\circ}, \underline{\mathbf{1 8 0}}, 202.5^{\circ}$, \\
$225^{\circ}$
\end{tabular}

\subsection{Preload factor effect}

In engineering, the appropriate preload is applied to each pad in order to prevent the fluttering of unloaded pads. Preload factors increased from 0.4 to 0.8 lead to radial bearing clearances decreased from 112 to $37.4 \mu \mathrm{m}$. Figure 3 compares the journal center orbits and dynamic minimum film thicknesses of a TPJB without static loads for five different preload factors. As the preload factor is increased, the orbit size and minimum film thickness are both decreased. To be specific, the orbit amplitude is decreased from 47.4 to $3.38 \mu \mathrm{m}(-92.9 \%)$, and the minimum film thickness is decreased from 56.8 to $19.0 \mu \mathrm{m}(-66.6 \%)$ with the preload factor increased from 0.4 to 0.8 . Figure 4 compares the journal center orbits and dynamic minimum film thicknesses of a TPJB with static loads for five different preload factors. As the preload factor is increased, the orbit center moves to the bearing center, and the orbit size and minimum film thickness are both decreased. To be specific, the $X$-direction amplitude is decreased from 22.5 to $3.16 \mu \mathrm{m}(-85.9 \%)$; the $Y$-direction amplitude is decreased from 21.6 to $3.16 \mu \mathrm{m}(-85.4 \%)$, and the minimum film thickness is decreased from 27.7 to $15.5 \mu \mathrm{m}(-44.2 \%)$ with the preload factor increased from 0.4 to 0.8 .
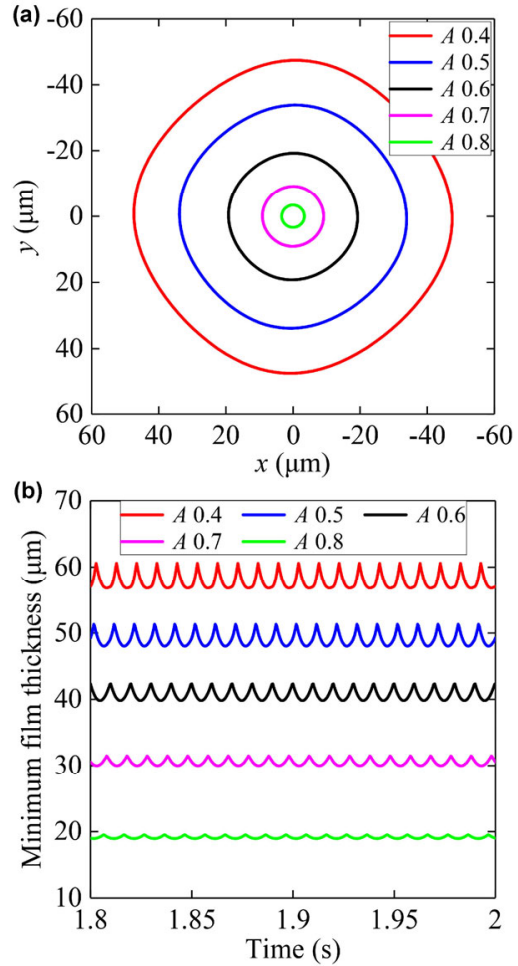

Fig. 3 (a) Journal center orbits and (b) dynamic minimum film thicknesses of a TPJB without static loads for different preload factors
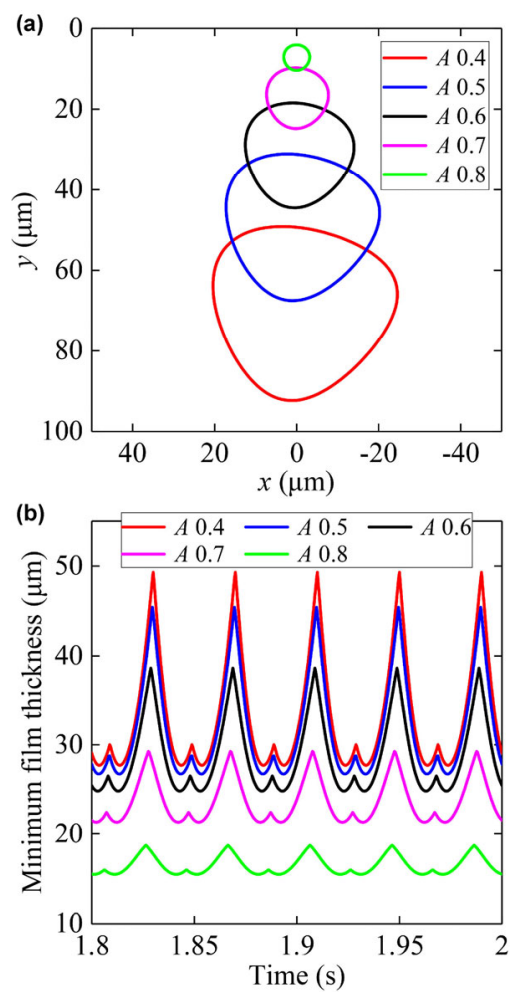

Fig. 4 (a) Journal center orbits and (b) dynamic minimum film thicknesses of a TPJB with static loads for different preload factors. 


\subsection{Pivot offset effect}

There are no equilibrium positions for pads if the pivot offset is greater than $81 \%$ in this case. Pivot offset of $50 \%$ means that the pivot supports on the center of pad back. Figure 5 compares the journal center orbits and dynamic minimum film thicknesses of a TPJB without static loads for five different pivot offsets. As the pivot offset is increased, the orbit size is decreased, and the minimum film thickness is increased first and then decreased. To be specific, the orbit amplitude is decreased from 33.9 to $8.16 \mu \mathrm{m}(-75.9 \%)$ with the pivot offset increased from $50 \%$ to $74 \%$. Moreover, there is a maximum value in minimum film thicknesses between pivot offsets of $50 \%$ and $62 \%$. Figure 6 compares the journal center orbits and dynamic minimum film thicknesses of a TPJB with static loads for five different pivot offsets. As the pivot offset is increased, the orbit center gradually moves to the bearing center; the orbit size is decreased, and the minimum film thickness is slightly increased first and then decreased. To be specific, the $X$-direction amplitude is decreased from 18.7 to $7.43 \mu \mathrm{m}(-60.3 \%)$, and the $Y$-direction amplitude is decreased from 18.2 to $7.42 \mu \mathrm{m}(-59.2 \%)$ with the pivot offset increased from $50 \%$ to $74 \%$. Likewise, there is a maximum value in minimum film thicknesses between pivot offsets of $50 \%$ and $62 \%$. Figure 7 shows the minimum film thicknesses and journal amplitudes of TPJBs with and without static loads as a function of pivot offsets. There is a maximum value of $51.0 \mu \mathrm{m}$ in minimum film thicknesses and an orbit amplitude of $22.6 \mu \mathrm{m}$ for a TPJB without static loads due to $55 \%$ pivot offset. The minimum film thickness is increased by $6.25 \%$ and the orbit amplitude is decreased by $33.3 \%$ with the pivot offset increased from $50 \%$ to $55 \%$. Moreover, there is a maximum value of $27.4 \mu \mathrm{m}$ in minimum film thicknesses, an $X$-direction amplitude of $16.2 \mu \mathrm{m}$ and a $Y$-direction amplitude of $15.8 \mu \mathrm{m}$ for a TPJB with static loads due to $53 \%$ pivot offset. The minimum film thickness is increased by $2.40 \%$; the $X$-direction amplitude is decreased by $13.7 \%$, and the $Y$-direction amplitude is decreased by $13.1 \%$ with the pivot offset increased from $50 \%$ to $53 \%$. Therefore, designers can significantly reduce the journal vibration and remain the minimum film thickness increased by designing an appropriate pivot offset.
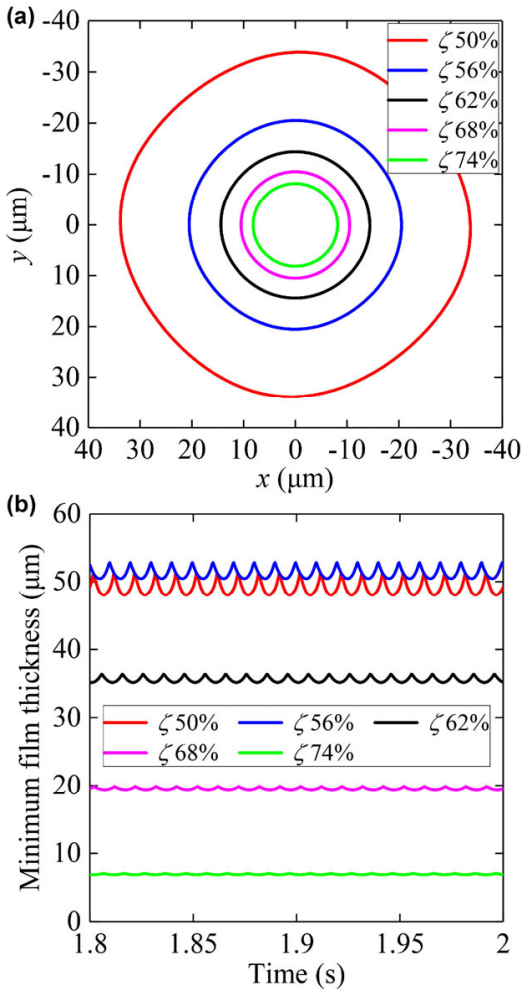

Fig. 5 (a) Journal center orbits and (b) dynamic minimum film thicknesses of a TPJB without static loads for different pivot offsets.
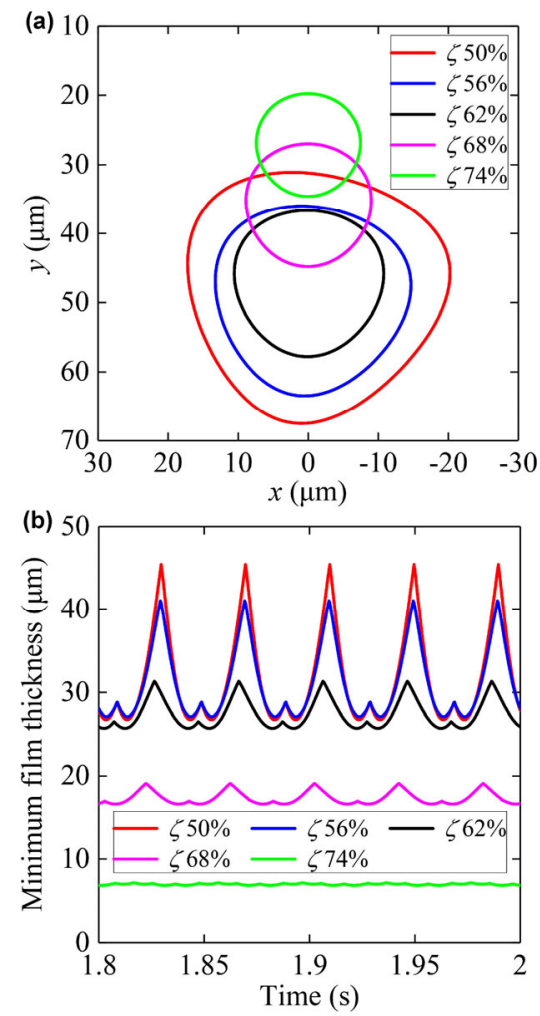

Fig. 6 (a) Journal center orbits and (b) dynamic minimum film thicknesses of a TPJB with static loads for different pivot offsets. 

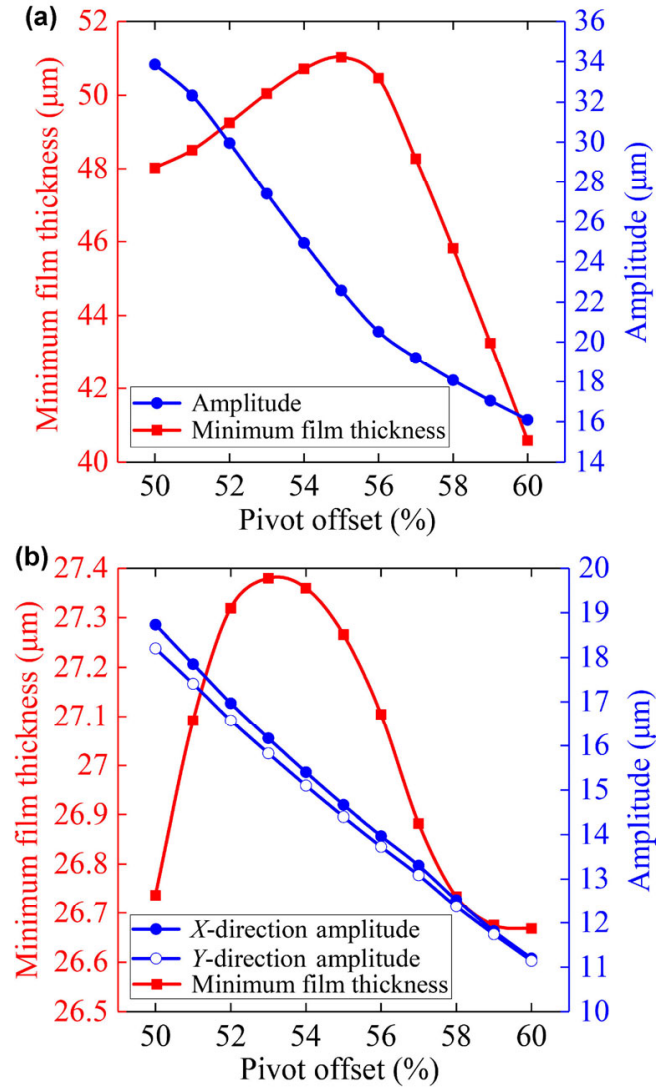

Fig. 7 Minimum film thicknesses and journal amplitudes of TPJBs (a) without and (b) with static loads as a function of pivot offsets.

\subsection{Length-to-diameter ratio effect}

Figure 8 compares the journal center orbits and dynamic minimum film thicknesses of a TPJB without static loads for five different length-to-diameter ratios. As the length-to-diameter ratio is increased, the orbit size is decreased, and the minimum film thickness is increased. To be specific, the orbit amplitude is decreased from 97.0 to $15.0 \mu \mathrm{m}(-84.5 \%)$, and the minimum film thickness is increased from 8.52 to $61.4 \mu \mathrm{m}$ (+6.21 times) with the length-to-diameter ratio increased from 0.3 to 1.5. Figure 9 compares the journal center orbits and dynamic minimum film thicknesses of a TPJB with static loads for five different lengthto-diameter ratios. As the length-to-diameter ratio is increased, the orbit center moves to the bearing center; the orbit size is increased first and then decreased, and the minimum film thickness is increased. To be specific, the maximum specific pressure of the bearing is decreased from 2.80 to $0.56 \mathrm{MPa}$, and the minimum film thickness is increased from 6.03 to $43.4 \mu \mathrm{m}$
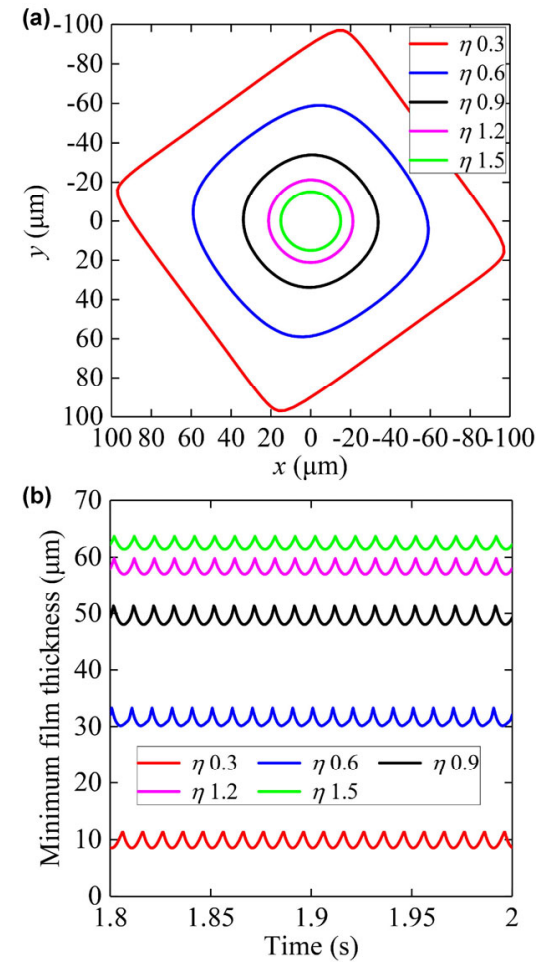

Fig. 8 (a) Journal center orbits and (b) dynamic minimum film thicknesses of a TPJB without static loads for different lengthto-diameter ratios.
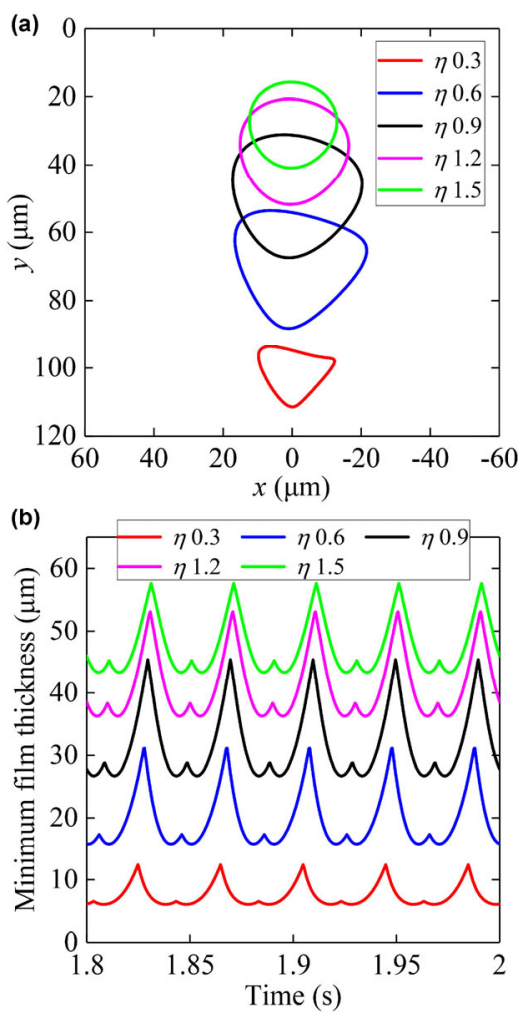

Fig. 9 (a) Journal center orbits and (b) dynamic minimum film thicknesses of a TPJB with static loads for different length-todiameter ratios. 
(+6.20 times) with the length-to-diameter ratio increased from 0.3 to 1.5. Moreover, there is a maximum value in orbit amplitudes between length-to-diameter ratios of 0.3 and 1.2. Figure 10 shows the journal amplitudes and minimum film thicknesses of a TPJB with static loads as a function of length-to-diameter ratios. There is a maximum value of $19.6 \mu \mathrm{m}$ in $X$-direction amplitudes and a minimum film thickness of $19.5 \mu \mathrm{m}$ due to 0.7 length-to-diameter ratio, and there is a maximum value of $18.6 \mu \mathrm{m}$ in $Y$-direction amplitudes and a minimum film thickness of $23.1 \mu \mathrm{m}$ due to 0.8 length-to-diameter ratio.

\subsection{Clearance ratio effect}

Clearance ratios increased from $0.6 \%$ o to $3 \%$ o lead to radial pad clearances increased from 124.8 to $624 \mu \mathrm{m}$ and radial bearing clearances increased from 62.4 to $312 \mu \mathrm{m}$. Figure 11 compares the journal center orbits and dynamic minimum film thicknesses of a TPJB without static loads for five different clearance ratios. As the clearance ratio is increased, the orbit size is increased, and the minimum film thickness is increased first and then decreased. To be specific, the orbit amplitude is increased from 13.1 to $272 \mu \mathrm{m}$ (+19.7 times) with the clearance ratio increased from $0.6 \%$ o to $3 \%$. Moreover, there is a maximum value in minimum film thicknesses between clearance ratios of $0.6 \%$ and $1.8 \%$. Figure 12 compares the journal center orbits and dynamic minimum film thicknesses of a TPJB with static loads for five different clearance ratios. As the clearance ratio is increased, the orbit center moves away from the bearing center; the orbit size is increased,

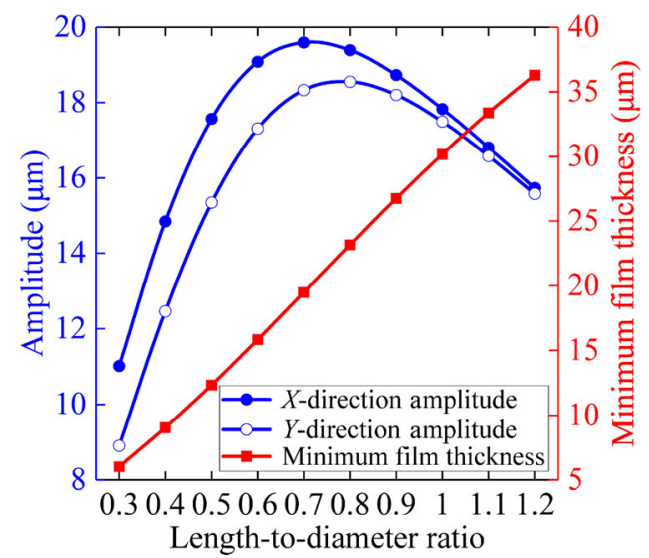

Fig. 10 Journal amplitudes and minimum film thicknesses of a TPJB with static loads as a function of length-to-diameter ratios.

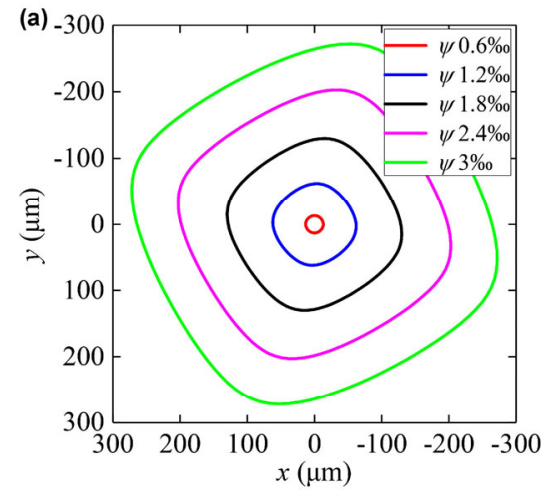

(b)

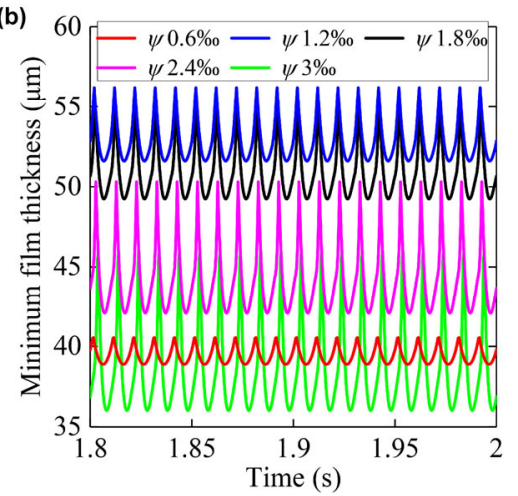

Fig. 11 (a) Journal center orbits and (b) dynamic minimum film thicknesses of a TPJB without static loads for different clearance ratios.
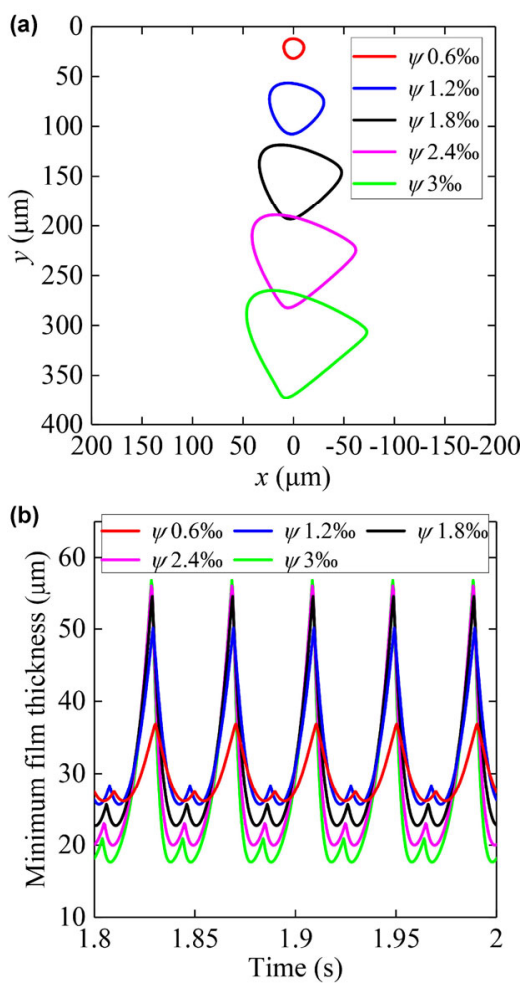

Fig. 12 (a) Journal center orbits and (b) dynamic minimum film thicknesses of a TPJB with static loads for different clearance ratios. 
and the minimum film thickness is decreased. To be specific, the $X$-direction amplitude is increased from 9.90 to $59.6 \mu \mathrm{m}$ (+5.02 times); the $Y$-direction amplitude is increased from 9.81 to $53.8 \mu \mathrm{m}$ (+4.49 times), and the minimum film thickness is decreased from 26.1 to $17.7 \mu \mathrm{m}(-32.5 \%)$ with the clearance ratio increased from $0.6 \%$ o to $3 \%$. Likewise, there could be a maximum value in minimum film thicknesses between clearance ratios of $0.6 \%$ and $1.2 \%$ due to the similar values at the two clearance ratios. Figure 13 shows the minimum film thicknesses and journal amplitudes of a TPJB with and without static loads as a function of clearance ratios. There is a maximum value of $51.9 \mu \mathrm{m}$ in minimum film thicknesses and an orbit amplitude of $72.4 \mu \mathrm{m}$ for a TPJB without static loads due to $1.3 \%$ o clearance ratio. Moreover, there is a maximum value of $26.8 \mu \mathrm{m}$ in minimum film thicknesses, an $X$-direction amplitude of $15.9 \mu \mathrm{m}$ and a $Y$-direction amplitude of $15.5 \mu \mathrm{m}$ for a TPJB with static loads due to $0.8 \%$ o clearance ratio. Therefore, designers can improve the bearing load capacity by designing an appropriate clearance ratio.
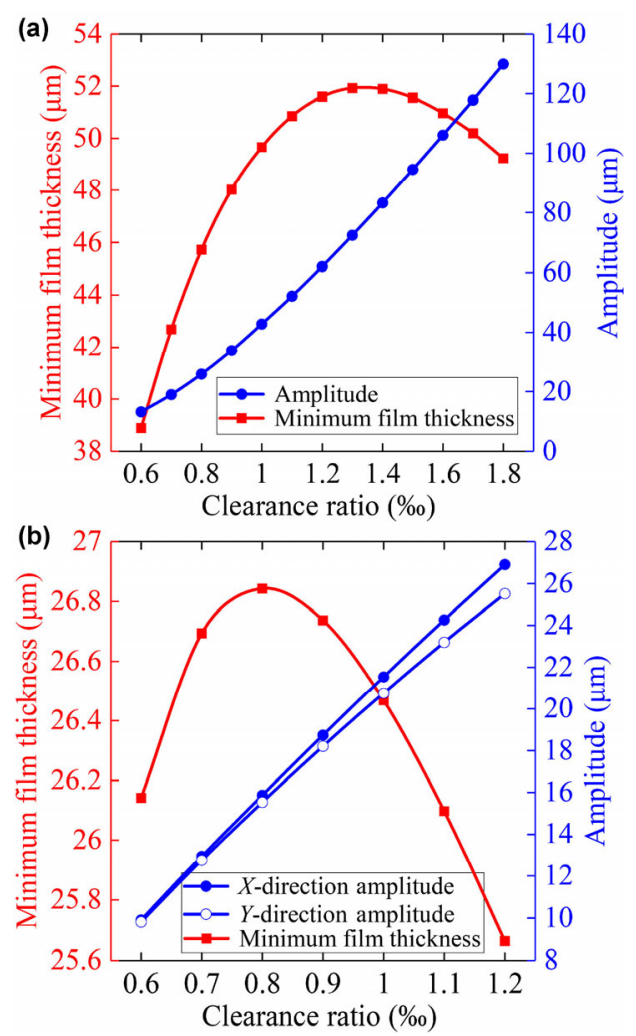

Fig. 13 Minimum film thicknesses and journal amplitudes of a TPJB (a) without and (b) with static loads as a function of clearance ratios.

\subsection{Pad arc angle effect}

Figure 14 compares the journal center orbits and dynamic minimum film thicknesses of a TPJB without static loads for five different pad arc angles. As the pad arc angle is increased, the orbit size is decreased, and the minimum film thickness is increased. To be specific, the orbit amplitude is decreased from 67.6 to $30.3 \mu \mathrm{m}(-55.2 \%)$, and the minimum film thickness is increased from 30.0 to $49.0 \mu \mathrm{m}$ (+63.3\%) with the pad arc angle increased from $45^{\circ}$ to $85^{\circ}$. Figure 15 compares the journal center orbits and dynamic minimum film thicknesses of a TPJB with static loads for five different pad arc angles. As the pad arc angle is increased, the orbit center moves to the bearing center; the orbit size is increased first and then tends to remain changeless, and the minimum film thickness is increased. To be specific, the $X$-direction amplitude is increased from 15.4 to $18.5 \mu \mathrm{m}(+20.4 \%)$; the $Y$-direction amplitude is increased from 13.6 to $18.1 \mu \mathrm{m}(+33.1 \%)$, and the minimum film thickness is increased from 16.1 to $27.9 \mu \mathrm{m}(+73.4 \%)$ with the pad arc angle increased from $45^{\circ}$ to $85^{\circ}$.
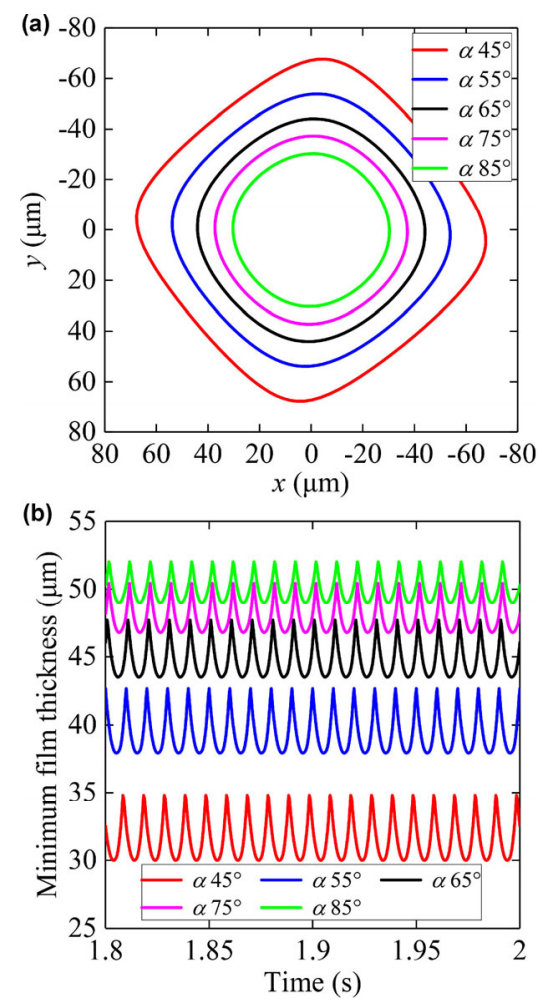

Fig. 14 (a) Journal center orbits and (b) dynamic minimum film thicknesses of a TPJB without static loads for different pad arc angles. 

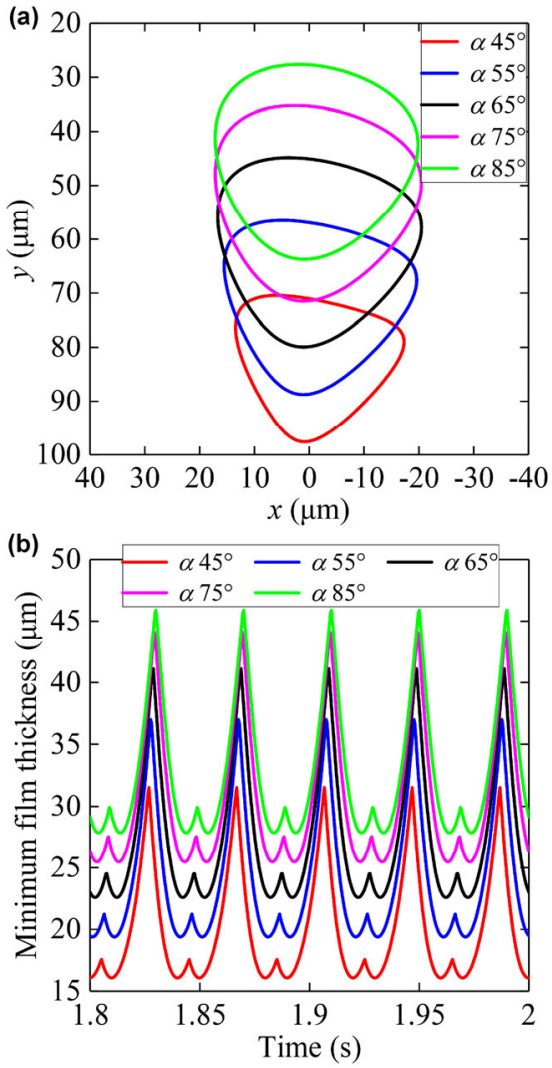

Fig. 15 (a) Journal center orbits and (b) dynamic minimum film thicknesses of a TPJB with static loads for different pad arc angles.

\subsection{Water temperature effect}

Water temperature can affect the density and viscosity of water film, and then affect the nonlinear dynamic performance of a TPJB. The temperature-densityviscosity relationship used in the calculation is listed in Table 2 . The density and viscosity are both decreased as the temperature is increased. Figure 16 compares the journal center orbits and dynamic minimum film thicknesses of a TPJB without static loads for five different water temperatures. As the water temperature is increased, the orbit size is increased and the minimum film thickness is decreased. To be specific, the orbit

Table 2 Temperature-density-viscosity relationship of water.

\begin{tabular}{ccc}
\hline Temperature $\left({ }^{\circ} \mathrm{C}\right)$ & Density $\left(\mathrm{kg} \cdot \mathrm{m}^{-3}\right)$ & Viscosity $(\mathrm{Pa} \cdot \mathrm{s})$ \\
\hline 10 & 999.7 & $1.3077 \times 10^{-3}$ \\
30 & 995.7 & $8.007 \times 10^{-4}$ \\
50 & 988.1 & $5.494 \times 10^{-4}$ \\
70 & 977.8 & $4.061 \times 10^{-4}$ \\
90 & 965.3 & $3.165 \times 10^{-4}$ \\
\hline
\end{tabular}

amplitude is increased from 20.3 to $36.7 \mu \mathrm{m}(+81.0 \%)$, and the minimum film thickness is decreased from 58.4 to $45.9 \mu \mathrm{m}(-21.3 \%)$ with the water temperature increased from 10 to $90{ }^{\circ} \mathrm{C}$. Figure 17 compares the journal center orbits and dynamic minimum film thicknesses of a TPJB with static loads for five different water temperatures. As the water temperature is increased, the orbit center moves away from the bearing center; the orbit size is increased, and the minimum film thickness is decreased. To be specific, the $X$-direction amplitude is increased from 14.9 to $19.2 \mu \mathrm{m}$ $(+28.4 \%)$; the $Y$-direction amplitude is increased from 14.8 to $18.5 \mu \mathrm{m}(+25.4 \%)$, and the minimum film thickness is decreased from 39.5 to $24.6 \mu \mathrm{m}(-37.7 \%)$ with the water temperature increased from 10 to $90^{\circ} \mathrm{C}$.

\subsection{Number of pads effect}

In this section, the research objects include three-pad, four-pad, five-pad, six-pad, and seven-pad TPJBs. The total arc angle of each TPJB is $320^{\circ}$. Figure 18 compares the journal center orbits and dynamic minimum film thicknesses of a TPJB without static loads for five
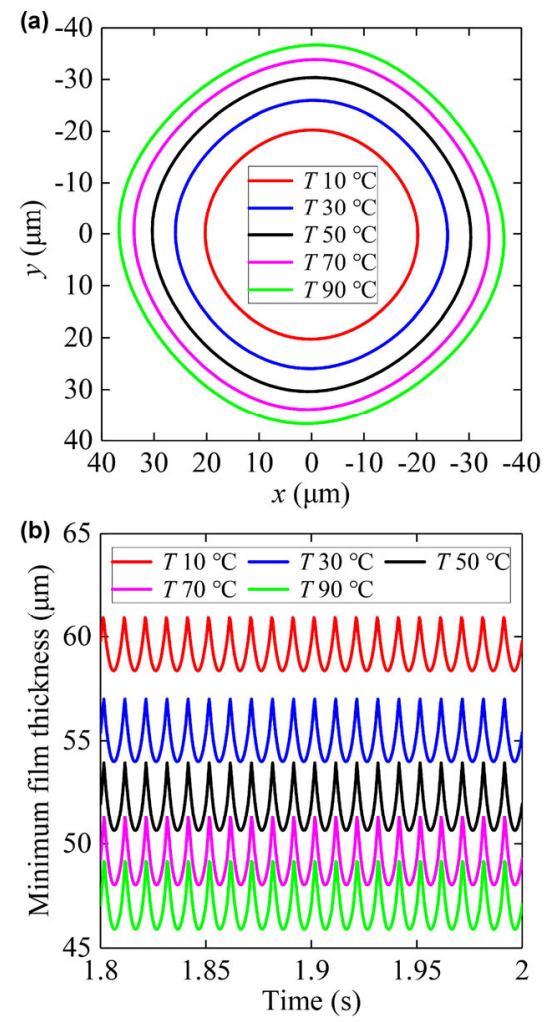

Fig. 16 (a) Journal center orbits and (b) dynamic minimum film thicknesses of a TPJB without static loads for different water temperatures. 

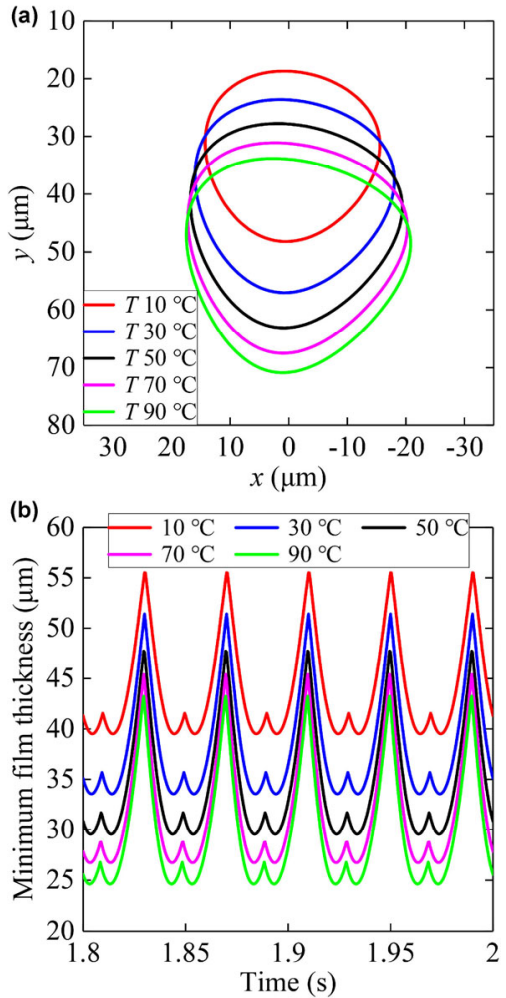

Fig. 17 (a) Journal center orbits and (b) dynamic minimum film thicknesses of a TPJB with static loads for different water temperatures.
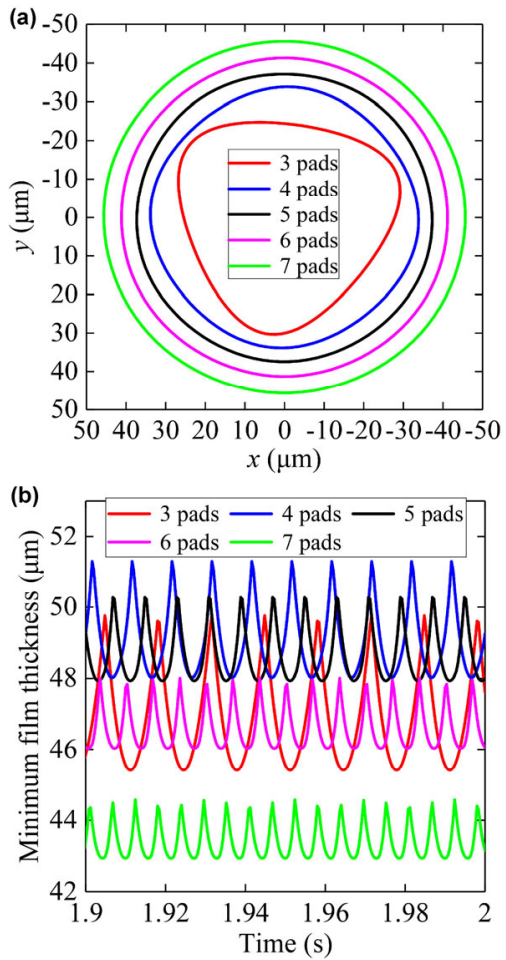

Fig. 18 (a) Journal center orbits and (b) dynamic minimum film thicknesses of a TPJB without static loads for different numbers of pads. different numbers of pads. As the number of pads is increased, the orbit size is increased, and the minimum film thickness is increased first and then decreased. To be specific, the $X$-direction amplitude is increased from 28.0 to $45.6 \mu \mathrm{m}(+63.1 \%)$, and the $Y$-direction amplitude is increased from 27.5 to $45.6 \mu \mathrm{m}$ (+65.6\%) with the number of pads increased from 3 to 7 . Moreover, there is a maximum value about $48.0 \mu \mathrm{m}$ in minimum film thicknesses for four-pad and five-pad TPJBs. Figure 19 compares the journal center orbits and dynamic minimum film thicknesses of a TPJB with static loads for five different numbers of pads. As the number of pads is increased, the orbit size is increased in $X$ direction and decreased in $Y$ direction, and the minimum film thickness is changeless first and then decreased. What is more, three-pad TPJBs result in a smaller $X$-direction amplitude; five and more-pad TPJBs result in a larger $X$-direction amplitude, and four-pad TPJBs result in similar amplitudes in both $X$ and $Y$ directions. To be specific, the $X$-direction amplitude is increased from 11.7 to $29.4 \mu \mathrm{m}$ (+1.52 times)
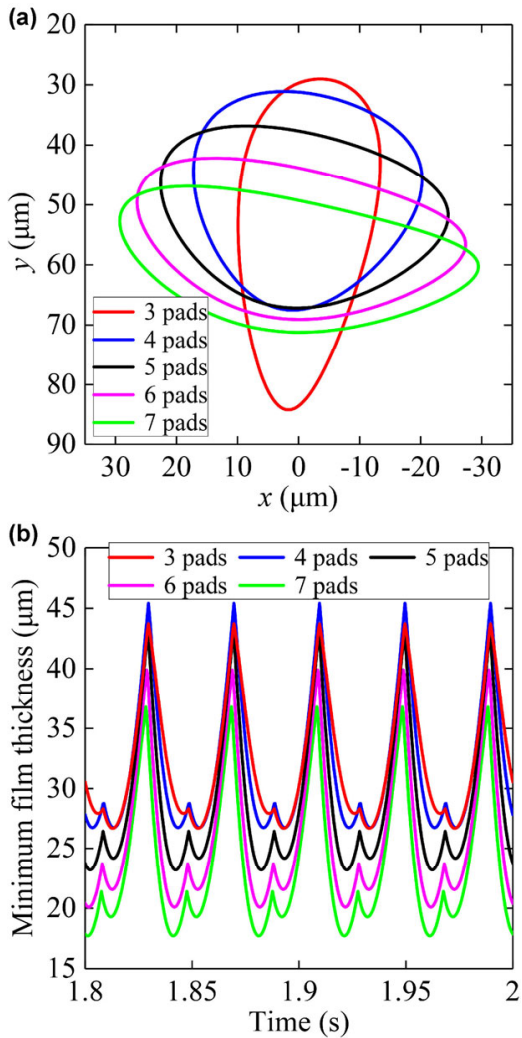

Fig. 19 (a) Journal center orbits and (b) dynamic minimum film thicknesses of a TPJB with static loads for different numbers of pads. 
and the $Y$-direction amplitude is decreased from 27.6 to $12.2 \mu \mathrm{m}(-55.9 \%)$ with the number of pads increased from 3 to 7 . Moreover, there is a maximum value about $26.7 \mu \mathrm{m}$ in minimum film thicknesses for three-pad and four-pad TPJBs.

\subsection{Load direction effect}

Figure 20 compares the journal center orbits and dynamic minimum film thicknesses of a TPJB with static loads for five different load direction angles. Load direction angles of $3 \pi / 4$ and $5 \pi / 4$ lead to the static load on pads, while load direction angle of $\pi$ leads to the static load between pads. With the static load on pads changed to that between pads, the loaddirection amplitude is increased from 12.4 to $18.2 \mu \mathrm{m}$ $(+46.7 \%)$; the vertical load-direction amplitude is decreased from 32.7 to $18.7 \mu \mathrm{m}(-42.6 \%)$, and the minimum film thickness is increased from 22.6 to $26.7 \mu \mathrm{m}(+18.2 \%)$.

\subsection{General design methodology}

A more general design methodology is given for TPJBs
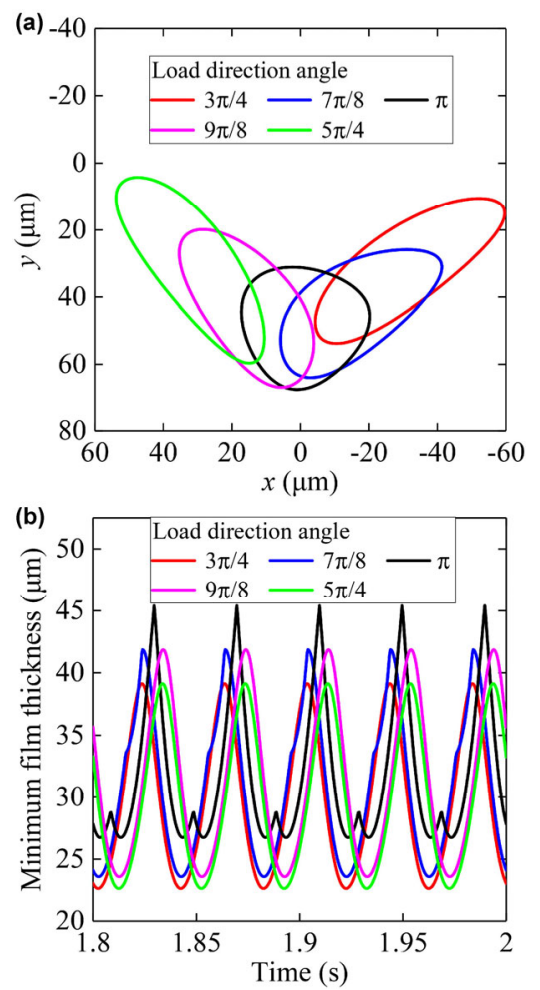

Fig. 20 (a) Journal center orbits and (b) dynamic minimum film thicknesses of a TPJB with static loads for different load directions. under dynamic loads from the perspective of vibration suppression and load capacity improvement. The main points are as follows:

i) Preload factors and pivot offsets are preferred to suppress the journal vibration because they belong to internal load adjustment parameters.

ii) Pivot offset of $50 \%$ is required for two directional machines, but an optimal pivot offset could be designed to improve the load capacity and suppress the vibration for unidirectional machines (55\% to $53 \%$ from 0 to $100 \mathrm{kN}$ loads in our case).

iii) An optimal clearance ratio could be designed to improve the load capacity ( $1.3 \%$ o to $0.8 \%$ o from 0 to $100 \mathrm{kN}$ loads in our case).

iv) A larger length-to-diameter ratio is recommended to avoid the vibration maximum and improve the load capacity (over 0.9 in our case).

v) Four-pad TPJBs with loads between pads are preferred due to the similar dynamic characteristics in load and vertical load directions and the high load capacity.

\section{Conclusions}

The current work performs a nonlinear dynamic analysis on journal center orbits and dynamic minimum film thicknesses of water-lubricated TPJBs with and without static loads for different bearing design parameters. The results could provide some design guidance for suppressing the vibration and improving the dynamic load capacity. In general, amplitudes can be suppressed by increasing preload factors and pivot offsets, and decreasing clearance ratios and water temperatures; minimum film thicknesses can be improved by increasing length-to-diameter ratios and pad arc angles, and decreasing preload factors and water temperatures. Several interesting conclusions can be briefly summarized as follows:

1) There is an optimal pivot offset and clearance ratio that can maximize the minimum film thickness, and the amplitude at the optimal pivot offset is smaller than that at $50 \%$ pivot offset.

2) There is a length-to-diameter ratio that can maximize the journal amplitude, which should be considered to avoid in the design.

3) From load on pads to load between pads, the 
amplitude is increased in the load direction, but the minimum film thickness is improved.

4) Four-pad and five-pad TPJBs without static loads and three-pad and four-pad TPJBs with static loads lead to optimal minimum film thicknesses.

5) Under static loads between pads, three-pad TPJBs lead to larger amplitudes in the load direction; five and more-pad TPJBs lead to smaller amplitudes in the load direction, and four-pad TPJBs lead to similar amplitudes in the load and vertical load directions, which can reflect the bearing dynamic characteristics in the two directions.

A synchronous motion and a safe minimum film thickness are desirable for a TPJB at the rated speed. In order to avoid nonsynchronous motions, the future work would investigate the effects of bearing design parameters on the bifurcation and stability of a water-lubricated TPJB.

\section{Acknowledgements}

This work is supported by National Basic Research Program of China (Grant No. 2015CB057303) and National Natural Science Foundation of China (Grant No. 51775412).

\section{Appendix}

Table A1 Dimensionless parameters and their dimensional ratios.

\begin{tabular}{cccc}
\hline Parameter & $\begin{array}{c}\text { Dimensional } \\
\text { ratio }\end{array}$ & Parameter & $\begin{array}{c}\text { Dimensional } \\
\text { ratio }\end{array}$ \\
\hline$P_{i}$ & $2 \mu \omega / \psi^{2}$ & $H_{i}, X, Y, \varepsilon, \varepsilon_{u}$ & $c$ \\
$\varepsilon^{\prime}, \varepsilon \theta^{\prime}$ & $\omega c$ & $X^{\prime \prime}, Y^{\prime \prime}$ & $\omega^{2} c$ \\
$M_{\mathrm{j}}$ & $\mu L /\left(\omega \psi^{3}\right)$ & $\bar{M}{ }$ & $\mu \omega R^{2} L / \psi^{2}$ \\
$\bar{J}$ & $\mu R^{2} L /\left(\omega \psi^{2}\right)$ & $F_{X}, F_{Y}, W_{X}, W_{Y}$ & $\mu \omega R L / \psi^{2}$ \\
$\tau$ & $1 / \omega$ & $\delta_{i}{ }^{{ }^{2}}$ & $\omega$ \\
$\delta_{i}{ }^{\prime \prime}$ & $\omega^{2}$ & $\lambda$ & $L / 2$ \\
\hline
\end{tabular}

Note: The dimensional ratio refers to the ratio of normalized parameters to dimensionless parameters.

Open Access This article is licensed under a Creative Commons Attribution 4.0 International License, which permits use, sharing, adaptation, distribution and reproduction in any medium or format, as long as you give appropriate credit to the original author(s) and the source, provide a link to the Creative Commons licence, and indicate if changes were made.

The images or other third party material in this article are included in the article's Creative Commons licence, unless indicated otherwise in a credit line to the material. If material is not in-cluded in the article's Creative Commons licence and your intended use is not permitted by statutory regulation or exceeds the permitted use, you will need to obtain permission directly from the copyright holder.

To view a copy of this licence, visit http:// creativecommons.org/licenses/by/4.0/.

\section{References}

[1] Wang Y C, Liu Y, Wang Z C, Wang Y M. Surface roughness characteristics effects on fluid load capability of tilt pad thrust bearings with water lubrication. Friction 5(4): 392-401 (2017)

[2] Fillon M, Wodtke M, Wasilczuk M. Effect of presence of lifting pocket on the THD performance of a large tilting-pad thrust bearing. Friction 3(4): 266-274 (2015)

[3] Kim S, Palazzolo A B. Bifurcation analysis of a rotor supported by five-pad tilting pad journal bearings using numerical continuation. J Tribol 140(2): 021701 (2018)

[4] Bai H Y, Liu X X, Li H G, Zhang W M, Meng G, Li M, Wang X H. Nonlinear dynamic characteristics of a large-scale tilting pad journal bearing-rotor system. $J$ Vibroeng 16(8): 4045-4064 (2014)

[5] Li M, Liu X X, Zhu R, Wang X H, Bai H Y, Li F C, Li H G, Meng G. Rotor dynamics behavior of tilting pad bearing supported turbo-expander considering temperature gradient. J Comput Nonlinear Dyn 11(2): 021004 (2016)

[6] Cha M, Glavatskih S. Nonlinear dynamic behaviour of vertical and horizontal rotors in compliant liner tilting pad journal bearings: Some design considerations. Tribol Int $\mathbf{8 2}$ : 142-152 (2015)

[7] Okabe E P. Analytical model of a tilting pad bearing including turbulence and fluid inertia effects. Tribol Int 114: 245-256 (2017)

[8] Abu-Mahfouz I, Adams M L. Numerical study of some nonlinear dynamics of a rotor supported on a three-pad tilting pad journal bearing (TPJB). J Vib Acoust 127(3): 262-272 (2005)

[9] Ying J Y, Jiao Y H, Chen Z B. Nonlinear dynamics analysis of tilting pad journal bearing-rotor system. Shock Vib 18(1-2): 45-52 (2011)

[10] Lu Y J, Ji L F, Zhang Y F, Wu Y, Liu Y Y, Yu L. Dynamic behaviours of the rotor non-linear system with fixed-tiltingpad journal bearings support. Proc Inst Mech Eng Part $J J$ Eng Tribol 224(10): 1037-1047 (2010) 
[11] White M F, Torbergsen E, Lumpkin V A. Rotordynamic analysis of a vertical pump with tilting-pad journal bearings. Wear 207(1-2): 128-136 (1997)

[12] Monmousseau P, Fillon M, Frêne J. Transient thermoelastohydrodynamic study of tilting-pad journal bearings under dynamic loading. J Eng Gas Turbines Power 120(2): 405-409 (1998)

[13] Brancati R, Rocca E, Russo R. Non-linear stability analysis of a rigid rotor on tilting pad journal bearings. Tribol Int 29(7): 571-578 (1996)

[14] Gadangi R K, Palazzolo A B. Transient analysis of tilt pad journal bearings including effects of pad flexibility and fluid film temperature. J Tribol 117(2): 302-307 (1995)

[15] Desbordes H, Fillon M, Wai C C H, Frene J. Dynamic analysis of tilting-pad journal bearing-influence of pad deformations. J Tribol 116(3): 621-627 (1994)

[16] Hei D, Lu Y J, Zhang Y F, Lu Z Y, Gupta P, Müller N. Nonlinear dynamic behaviors of a rod fastening rotor supported by fixed-tilting pad journal bearings. Chaos Solitons Fractals 69: 129-150 (2014)

[17] Okabe E P, Cavalca K L. Rotordynamic analysis of systems with a non-linear model of tilting pad bearings including turbulence effects. Nonlinear Dyn 57(4): 481-495 (2009)

[18] Armentrout R W, He M H, Haykin T, Reed A E. Analysis of turbulence and convective inertia in a water-lubricated

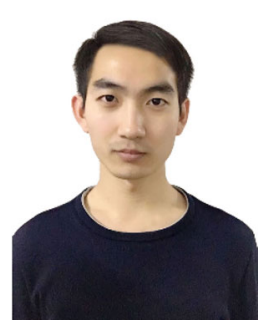

Yingze JIN. He received his bachelor degree in industrial design in 2014 from Zhengzhou University, Zhengzhou, China. After then, he was a Ph.D. student in mechanical

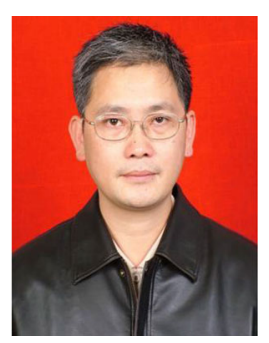

Xiaoyang YUAN. He received his M.S. and Ph.D. degrees in mechanical engineering from Xi'an Jiaotong University, Xi'an, China, in 1985 and 1994, respectively. He is currently a professor in the Key tilting-pad journal bearing using conventional and CFD approaches. Tribol Trans 60(6): 1129-1147 (2017)

[19] Li Y, Wang D Z, Gu W G. Study on the dynamic characteristics of the water-lubricated tilting-pad radial bearing considering temperature-viscosity effect. In Proceedings of the 2014 22nd International Conference on Nuclear Engineering, Prague, Czech Republic, 2014: 1-6.

[20] Jin Y Z, Shi Z Y, Zhang X J, Yuan X Y. Rapid solution for analysis of nonlinear fluid film force and dynamic behavior of a tilting-pad journal bearing-rotor system with turbulent and thermal effects. Friction (2019). doi: 10.1007/s40544019-0263-9 (in Press)

[21] Taylor C M, Dowson D. Turbulent lubrication theory application to design. J Lubr Technol 96(1): 36-46 (1974)

[22] Taniguchi S, Makino T, Takeshita K, Ichimura T. A thermohydrodynamic analysis of large tilting-pad journal bearing in laminar and turbulent flow regimes with mixing. J Tribol 112(3): 542-548 (1990)

[23] Bouard L, Fillon M, Frêne J. Comparison between three turbulent models - application to thermohydrodynamic performances of tilting-pad journal bearings. Tribol Int 29(1): 11-18 (1996)

[24] Jin Y Z, Chen F, Zhang F, Yuan X Y. Nonlinear dynamic performance of tilting-pad journal bearing with adjustable elastic pivot design. Tribol Int 136: 533-547 (2019)

engineering at the Key Laboratory of Education Ministry for Modern Design and Rotor-Bearing System, Xi'an Jiaotong University, Xi'an, China. His research interests include hydrodynamic bearings and rotor dynamics.

Laboratory of Education Ministry for Modern Design and Rotor-Bearing System, Xi'an Jiaotong University. His research areas cover superconducting magnetic technology, modern design and control of electromechanical system, lubrication theory, and dynamics of rotor-bearing-seal system. 